\title{
THE USE OF SOCIAL MEDIA IN PORTUGUESE COMPANIES: EMPIRICAL STUDY WITH SMES PROTOCOLATED WITH ESTGA-UA
}

\author{
S. Estrela, D. Baptista \\ Águeda School of Technology and Management - University of Aveiro (PORTUGAL)
}

\begin{abstract}
In the last five years, portuguese government policies and european guidelines have been reinforcing the promotion of strategies that foster innovation, access to the digital market and the creation of conditions to optimize the growth potential of companies in the digital context. Digital innovation is inevitably contributing to accelerate the change of organizations in terms of business models, but also of communication and professional skills required. The way that information has been shared and received has changed the way that companies work and communicate. This is why a significant number of companies, particularly small and medium sized companies, at the time of recruiting they value the skills to use communication tools and digital technologies that enable to create and share content, including more Social Media - like Facebook, Youtube, Instagram, Twitter or Linkedin. In Europe, it is expected that 16 million new jobs will be created by 2020 which will require information and technology (IT) skills. In Portugal, according to the Minister of Education, in 2030, about $80 \%$ of the population will have digital skills and $8 \%$ will be specialists in information and communication technologies. This reality demands a work of joint reinforcement and partnership between the companies and educational establishments responsible for the training of young professionals in all areas. This evidence and necessity justify the present study whose data were obtained through the administration of an online questionnaire survey to a sample $(\mathrm{N}=89)$ of Small and Medium Enterprises (SME) protocols with the Águeda School of Technology and Management - University of Aveiro (ESTGA-UA), in Portugal, within the scope of the curricular internships of the Degree in Retail Management and the Higher Education Training Course (TESP) in SME Management.
\end{abstract}

The study aims to make a diagnosis that allows to know the reality and to draw the digital picture of these companies and tries to verify how these SMEs are responding to the challenges of digital communication in three dimensions: to identify the social media used and the importance attributed to it; assess whether SMEs have a strategy for managing and producing digital content; and identify the profile of the person responsible for the production/management of these contents. The results show that SMEs use social media to communicate, although they do not have a defined communication strategy and the focus of communication is too focused on the company and its products/services. Moreover, even though they recognize the excellent oral and written knowledge of the language as an essential requirement for content production, this task is carried out in many cases by internal workers without specific training and who add this function to others. It is intended that this study contribute to a reflection on the higher education provided and its suitability to the needs of these companies in an increasingly global and digital economy.

Keywords: ESTGA-UA, digital competences, digital communication, SME, social media.

\section{INTRODUCTION}

Learning, productivity and competitiveness are variables that are increasingly dependent on digital technology and that drive the growing dominance of digital skills for the pursuit of different professions and greater investment by SMEs in technology innovation.

In the business context, the European guidelines have supported the development of broadband networks and digital service infrastructures (Regulation (EU) N. ${ }^{\circ}$ 283/2014 of the European Parliament and of the Council of 11 March 2014) and the strategies defined by the European Commission to ensure the creation of the Digital Single Market, in order to improve consumer and business access to digital goods and services, to create fair and equitable conditions for the development of digital networks and innovative services, and to optimize the potential growth of the global and digital economy.

In Portugal, we can emphasize the government policies that have fostered innovation and the adoption of new industrial policies to create value-added products and services for international markets (Council of Ministers Resolution N. 112/2012 of 31 December 2012), and initiatives to 
encourage SME: SME Digital, which encourages SMEs to use digital tools, to access new markets, better management and to make their relationship with customers and suppliers more efficient [1]; and the Industry 4.0 Initiative, which drives the adoption of technologies and processes associated with Industry 4.0. [2].

This digital transformation also inevitably leads to a change in the communication paradigm. Portugal's growing trend towards digitalization [3] and the constant use of digital platforms ${ }^{1}$, associated to the number of new support communication that companies have to communicate and relate to their audiences, among which social networks ${ }^{2}$ - the most visible digital platforms of social interaction, have led to changes in attitudes, behaviors and work spaces [4], and a closer proximity between companies and users of these same platforms. Through the Website, Blog and especially social networks, companies can communicate knowledge, trends and all their products and services, but above all ensure that the communication process is more effective, because it is more immediate. However, for this proximity relationship to be assumed as a strategic and integrated communication, it should require the adaptation of the shared contents in digital environments and adjust companies online behavior to the expectations and language of their targets, as well as a connection "in social sharing of content" [5], which is also interesting, relevant and useful for users as well. And this will certainly require a cadre of collaborators specialized in the area of digital communication or, at least, the domain of specific competencies by the employees who assume the role of creators and content managers.

In the context of learning, according to the National Digital Competencies Initiative e.2030 [6], Portugal intends to position itself on the top of European countries in digital competences by responding to three major challenges: the generalization of digital literacy, by stimulating employability and participation in internationalization networks for innovation and development. Therefore, it is vital to strengthen efforts to learn digital skills in order to prepare the population for the digital professional context.

The inclusion of digital competence among the eight key competences for lifelong learning $[7]^{3}$, the creation of the DigComp 2.0: The Digital Competence Framework for Citizens [8], which defines 5 areas of digital competence (including Communication and Collaboration and Digital content creation) and which was complemented with the version 2.1. in $2017^{4}$ [9] and the National Digital Competence Initiative e2030 - Portugal INCoDe.2030 (2017) are important efforts in the learning of digital competences and justify the adequacy of curricula of the different levels of education, specifically of higher education polytechnics, to the needs of the labor market and global digital economy [10].

In fact, everything seems to converge towards a commitment to the digital economy, which requires a strong commitment of everyone - companies, institutions of higher education and students - to develop digital skills. In this sense, and in view of the privileged link of Águeda School of Technology and Management - University of Aveiro to the surrounding community through protocols with companies and public-private institutions through internships and projects carried out in cooperation with companies, the question arises: Are SMEs protocoled with ESTGA-UA, within the scope of the curricular internships of the Degree in Retail Management and the Higher Education Training Course in SME Management, prepared to respond to the challenges of digital communication?

\footnotetext{
${ }^{1}$ Digital platform, also referred as information and communication technologic platform, is any technological structure with an interface that allows information sharing, transactions and connections to and between users.

2 Platforms whose information architecture is mainly focused on social interaction, through the sharing of content, and that integrate Facebook, Twitter, Youtube, Instagram, among others, including Linkedin (social network of a more professional character).

${ }^{3}$ The Key Competences for Lifelong Learning - A European Reference Framework identifies eight key competences each European citizen needs for personal fulfilment and development, employment, social inclusion and active citizenship: 1) Communication in the mother tongue; 2) Communication in foreign languages; 3) Mathematical competence and basic competences in science and technology; 4) Digital competence; 5) Learning to learn; 6) Social and civic competences; 7) Sense of initiative and entrepreneurship; and 8) Cultural awareness and expression.

${ }^{4}$ According to the DigComp 2.0 [7], the 5 Areas of Digital Competence are: 1) Information and data literacy; 2) Communication and Collaboration; 3) Digital content creation; 4) Safety; 5) Problem solving.

The version DigComp 2.1 extends the three initial levels of proficiency to a more detailed eight-level description and aims to support the interested in further implementing DigComp.
} 
This is the central issue of a more embracing and ongoing study which seeks to assess how SMEs ${ }^{5}$ are responding to the challenges of digital communication. In this article, the results presented will be only those that will allow: to identify the digital platforms used by SMEs and the degree of importance that companies give them; to list the objectives and typologies of the contents produced; to assess if the content manager is an employee who has been hired specifically to perform this function or if this function is added to other; to learn about their training and identify the most valued requirements when hiring a digital content manager/producer ${ }^{6}$.

\section{METHODOLOGY}

The data were obtained by applying a questionnaire survey to a sample of $89 \mathrm{SMEs}^{7}$.The survey was available online from April 21 to May 21, 2018, and was addressed to the managers or the responsible of the Communication Departments of the SME protocoled with ESTGA-UA, within the scope of the curricular internships of the Degree in Retail Management and the Higher Education Training Course in SME Management

The survey is structured into two parts: the first one includes three questions that characterize the respondent (age, gender and schooling) and five that characterize the company (size, number of employees, municipality, economic activity, and name (optional)); the second is made up of 17 questions regarding the digital platforms used by companies to communicate. The questions are mostly closed (some semi-open and open) and multiple choice, category type, grid, list and scale (using the Likert scale, with five propositions). 12 of the 17 questions on digital communication are presented and discussed in this article: (1) Does your company use digital platforms to communicate? (2) If "no", what are the reasons why your company does not use digital communication platforms? (3) If "yes", what digital communication platforms are used and how important is it to you? (4) How often the contents are updated on the digital communication platforms used by your company? (5) Do you monitor social networks at the weekend? (6) Does the company define a content plan in advance? (7) What are the targeted objectives with the use of digital platforms? (8) What is the typology of shared content? (9) Who manages digital content? (10) If the content manager/producer is an "internal worker", has he been hired specifically to perform the function or does he accumulate that function with some others? (11) What is the training area of the internal worker responsible for the management/production of digital content? (12) What are the most valued requirements when hiring a digital content manager/producer?

The data obtained are treated using descriptive statistics techniques and using the Statistical Package for Social Sciences (SPSS) software, version 25.

\section{RESULTS}

Eighty-nine valid responses were obtained, $51(57 \%)$ of males and $38(43 \%)$ of females. Three (or $3.4 \%)$ of the 89 participants are under 25 years; $10(11.2 \%)$ are between 25 and 30 years old; 14 $(15.7 \%)$ between 31 and 35 years; $16(18 \%)$ between 36 and 40 years; $14(15.7 \%)$ between 41 and 45 years; 16 (18\%) between 46 and 50 years; 10 (11.2\%) between 51-55 years; 4 (4.5\%) between 56 and 60 years; $2(2.2 \%)$ between the ages of 61 and 65 years.

As far as level of education is concerned, 64 (or $71.9 \%$ ) of the participants are holders of higher education (45 graduates, 13 masters, 4 bachelors, 1 doctor, and 1 postgraduate), 15 hold the 12th year; 5 the $9^{\text {th }}$ year; 4 the $6^{\text {th }}$ year and 1 holds a Technological Specialization Course.

The answers came from 42 micro-enterprises, 23 small and 24 medium-sized, distributed in 29 municipalities in mainland Portugal, with the most important being Águeda, Aveiro and Oliveira do

${ }^{5}$ Small and medium-sized enterprises (SMEs) are defined in the European Union Recommendation 2003/361 of May 6, 2003 : Medium-sized enterprises employ less than 250 persons and have an annual turnover not exceeding EUR 50 million or whose annual balance sheet total does not exceed EUR 43 million; a small enterprise has less than 50 employees and an annual turnover or total annual balance sheet not exceeding EUR 10 million; and a micro-enterprise employs less than 10 persons and its annual turnover or total annual balance does not exceed EUR 2 million.

${ }^{6}$ Digital content may consist of images, sound, videos, among other forms of information transmission shared through digital platforms.

${ }^{7}$ ESTGA is protocoled with 483 organizations and 115 have already hosted curricular internships of the Degree in Retail Management and the Higher Education Training Course in SME Management. Thus, in this universe of 115 the sample of 89 SMEs was withdrawn to ensure representativeness. 
Bairro (with $44 \%$ of total responses) and activities in 10 of the main sections of the Portuguese Classification of Economic Activities, Rev. 3.

\subsection{Does your company use digital platforms to communicate?}

Of the 89 companies surveyed, 87 (or $97.8 \%$ ) use digital platforms. The non-use of these platforms by $2(2.2 \%)$ SMEs is justified by the scarcity of material resources and people with skills to use and take advantage of the potential of these platforms.

\subsection{What digital communication platforms are used and how important is it to you?}

SMEs surveyed use multiple platforms, with only 6 cases (or $6.9 \%$ ) using a single digital platform to communicate (2 SMEs only use the Website and 4 only use Facebook).

Chart 1 shows that the most used platform is Facebook (81 or $93.1 \%$ of SMEs surveyed), followed by the Website (79 or $90.8 \%$ ); Linkedin (64 or $73.6 \%$ ); YouTube (59 or $67.8 \%)$; Google+ (58 or $66.7 \%$ ); and Instagram (52 or $59.8 \%$ ). In contrast, the Blog is the least used (44, or $50.6 \%$ ), followed by Online Store and Pinterest (both used by 45 PME, i.e. $51.7 \%$ of participating companies) and Twitter (48 or $55.2 \%)$.

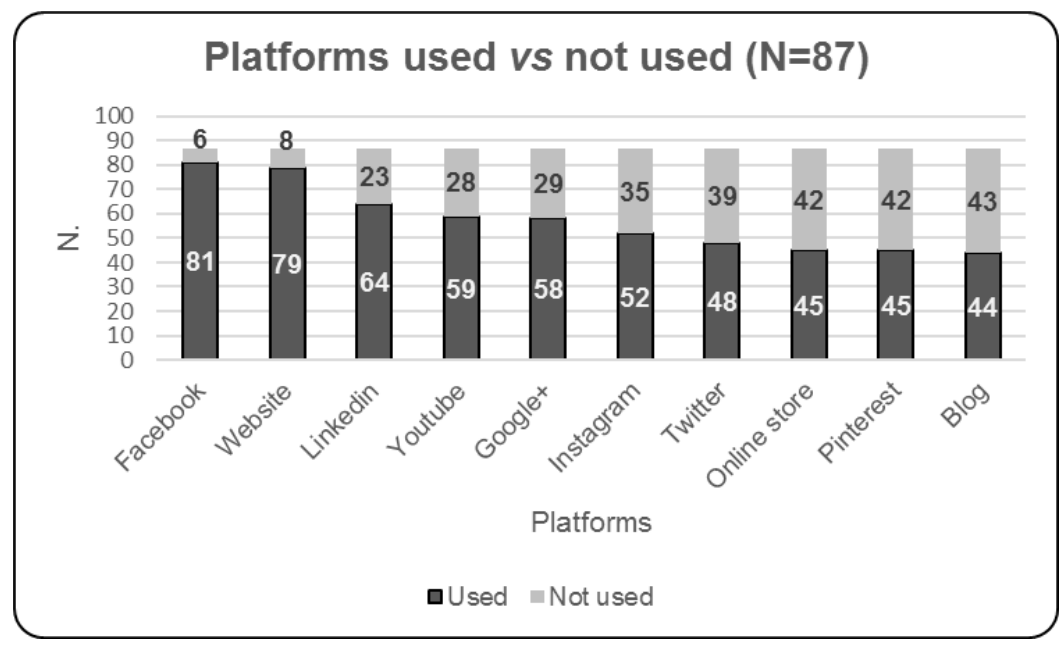

Chart 1. Platforms used vs not used

Participants were asked to assign a degree of importance to the platforms used (on a scale where 1 means unimportant and 5 extremely important). The results show that the three most used platforms are also the most valued, the Website obtained an average of 4.2 values ( $46.8 \%$ consider it extremely important), followed by Facebook with 3.6 and Linkedin with 3.4 values). The Online Store, despite being one of the least used platforms, is the fourth most valued (3.1 values), followed by Google+ (2.9), YouTube (2.8), Instagram (2.7), Blog 2.1), Twitter (2) and Pinterest (1.8).

\subsection{How often the contents are updated on the digital communication platforms used by your company?}

The digital content is updated with a very heterogeneous periodicity. Facebook is one of the most regularly updated platforms, since 54 (or $74 \%$ ) of SMEs who use it claim to update it at least once a week ( 16 or $21.9 \%$ update every day, 17 or $23,3 \%$ do it two or more times a week, and 21 or $28.8 \%$ do updates one to two times a week). Instagram, despite being used by only 52 of the surveyed SMEs, 3 (or $12.5 \%)$ update it daily; $9(37.5 \%)$ three or more times a week, $7(29.2 \%)$ once or twice a week. The online store, globally, one of the least used platforms, is updated daily by 6 (or $22.2 \%$ ) SMEs. 
In the case of platforms less used by the companies, it is verified that the updating period is greater than one year (the 35 or $77.7 \%$ SMEs that use Pinterest, the 30 or $62.5 \%$ that use Twitter, and the 26 or $59.1 \%$ that use the Blog).

\subsection{Do you monitor social networks at the weekend?}

Globally few companies monitor social networks over the weekend, with the exception of Facebook (66 or $81.5 \%$ of the 81 companies that use this network to update contents at the weekend). Instagram is updated by 21 (or $40.4 \%$ ) of the 52 SMEs that use it; Linkedin by 22 ( or $34.4 \%$ ) of the 64 companies; Google+ for 16 (or 27.6\%) of the 58 SMEs; Youtube by 11 (or 18.6\%) of the 59 companies; Twitter for 7 ( or $14.6 \%$ ) of the 48 SMEs; and Pinterest for 2 ( or $4.4 \%$ ) of the 45 companies that use it.

\subsection{Does the company define a content plan in advance?}

In 52 (or $60 \%$ ) of cases, the content plan is not defined in advance.

\subsection{What are the targeted objectives with the use of digital platforms?}

When questioned about the objectives targeted by SMEs with the use of the platforms, as shown in table 1, 67 of the participants indicated the options "To make known the company and its products/services"; "To favor proximity to customers" (58); "To raise new customers" (53); "To ensure visibility to the public and partners" (53); "To generate sales" (43); and "To gain public confidence". As less valued objective point "To communicate more segmented" (21) and "To communicate more efficiently" (34).

Table 1. Company's presence on digital platforms aims

\begin{tabular}{l|c|c}
\hline \hline Company's presence on digital platforms aims to: & Frequency & $\%$ \\
\hline To make known the company and its products/services & 67 & 18,4 \\
\hline To favor proximity to customers & 58 & 15,9 \\
\hline To raise new customers & 53 & 14,6 \\
\hline To ensure visibility to the public and partners & 53 & 14,6 \\
\hline To generate sales & 43 & 11,8 \\
\hline To gain public confidence & 35 & 9,6 \\
\hline To communicate more efficiently & 34 & 9,3 \\
\hline To communicate more segmented & 21 & 5,8 \\
\hline Total & 364 & 100,0 \\
\hline \hline
\end{tabular}

\subsection{What is the typology of shared content?}

Not being the intention of the study to specify the content format shared by SMEs, it was only intended to know their informational typology, being verified that 66 companies publish content directly related to their activity; 52 use the platforms to launch new products/services; Presence in national and international fairs (40); institutional videos (31) presence in social events (30); Awards and honourable mentions attributed to the company (27); recruitment processes (24); content indirectly related to the company's activity (21); and Entertainment (9). Four participants report that they have not published content recently (Table 2 ). 
Table 2. Shared content typology.

\begin{tabular}{l|c|c}
\hline \hline Published content: & Frequency & $\%$ \\
\hline Directly related to company activity & 66 & 21,7 \\
\hline Launch of new products / services & 52 & 17,1 \\
\hline Presence in national and international fairs & 40 & 13,2 \\
\hline Institutional videos & 31 & 10,2 \\
\hline Presence in social events & 30 & 9,9 \\
\hline Awards and honourable mentions attributed to the company & 27 & 8,9 \\
\hline Recruitment processes & 24 & 7,9 \\
\hline Indirectly related to company activity & 21 & 6,9 \\
\hline Entertainment & 9 & 3,0 \\
\hline Have not published recent content & 4 & 1,3 \\
\hline Total & 304 & 100,0 \\
\hline \hline
\end{tabular}

\subsection{Who manages digital content and what is the training area?}

The contents are managed in $76(87.4 \%)$ SMEs by internal workers, $9(10.3 \%)$ by one agency and 2 $(2.3 \%)$ by a subcontracted freelancer (Chart 2$)$.

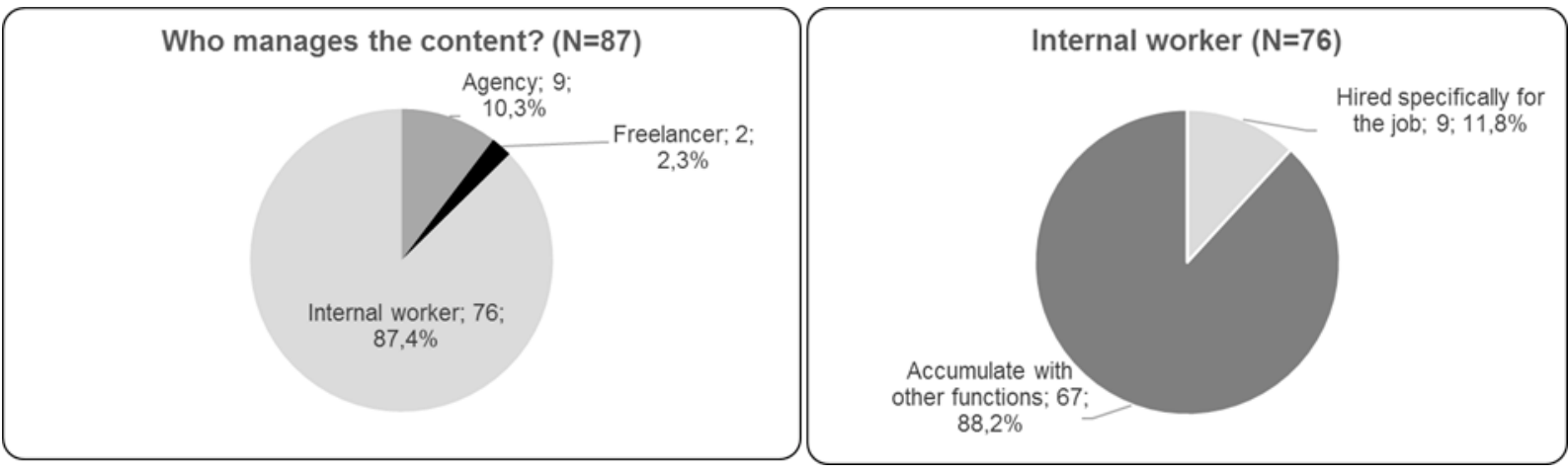

Chart 2 - Who manages the contents

Chart 3 - Functions of who manages the contents

Of the 76 internal workers who manage digital content (Chart 3 ), only $9(11.8 \%)$ were hired specifically for this function, the remaining $67(88.2 \%)$ accumulate this function with some other.

There is some diversity in the training of internal workers responsible for the management/production of internal contents: $28(36.8 \%)$ have a degree in Marketing; $8(10.5 \%)$ are graduated in Management, the same number of those graduated in IT (10.5\%); 7 (9.2\%) workers have Communication training; 6 $(7.9 \%)$ in Secretariat/Advisory; 1 (1.3\%) graduated in Design and another in Ecotourism $(1,3)$. The remaining $17(22.4 \%)$ workers did not have specific training to perform the function.

\subsection{What are the most valued requirements when hiring a digital content manager/producer?}

In a closed question, the respondents were asked to indicate their degree of importance (on a scale where 1 means unimportant and 5 extremely important) with six affirmations given. They consider it very important for content managers to have an "Excellent oral and written expression in Portuguese" (average 4.3 values), followed by "Mastering of image and video editing programs " (3.9).The "Domain oral and written English and/or another foreign language," the "Search Engine Optimization knowledge" and "Production of videos and images" with an average of 3.7 values, and finally, "Webdesigner knowledge", with an average of 3.6 values. 


\section{DISCUSSION}

The data reveal, as in other studies [11] [12], that SMEs adopt digital technologies in an increasingly digital and global economy and, therefore, also more competitive.

The emphasis given to the social interaction platform Facebook seems to be justified for being the second most used social network by the Portuguese [13]. However, the fact that the Website was considered the most important platform means that companies recognize it as a platform-based on the digital communication strategy, which presents itself as a "gateway" to the company through web search engines, which allows users to be forwarded to the other communication channels.

Despite the efforts of SMEs to use and update digital platforms, the periodicity with which they do is still far from what is expected, given that the Internet has a penetration rate of $75 \%$ in Portugal and that $85 \%$ of the Portuguese population accesses to the Internet every day (on average the Portuguese spend $6 \mathrm{~h} 31$ minutes daily on the internet and $2 \mathrm{~h} 10$ minutes in social media) [13]. This seems to indicate that the corporate communication strategy is not aligned with the habits/needs of users/potential consumers. In addition, the results also show that few companies monitor digital platforms over the weekend, with the exception of Facebook (81.5\%). What somehow opposes the importance that authors attribute to the need for constant monitoring of what is shared online about the company and/or brand [14], since it is often this supervision that companies obtain a consumer's opinion on a product, service and/or brand and assesses its degree of recommendation [15].

In the case of social networks, which are platforms of social interaction per excellence, companies use them essentially to promote the company, their products and services. This also seems to show that social networks are not used specifically to build a community surrounding the organization, created through contents of value for its activity [16] and as "channels of content circulation and conversations based on different representations of the world" [5].

More than half of the SMEs surveyed (52 or $60 \%$ ) admit not having a content plan in advance elaborated. This seems to show, in these cases, the lack of an integrated strategy communication, that responds to the "expectations and language of its targets" [14] and which is based on a mechanism of tactical actions that will divide themselves into communication action plans with a clearly delimited deadline, in order to achieve the objectives defined a priori [17]. The anticipated content planning becomes fundamental for the alignment between digital communication and the organization objectives and mission, conceived and planned by the Organizational Communication, as well with the strategic goals of the organization, reached by the Strategic Communication.

The existence of a content plan by the companies will also guarantee a strategic digital presence at three essential levels: own presence, through the contents built with the company brand and disclosed by the organization itself in the company's Website, in Blog, and through the profiles in different social networks (Facebook, Youtube, Twitter, Linkedin,...); the free presence (or organic gain) obtained through comments, sharing and content generated by others in social networks, as well as the results obtained through organic search in web search engines (example Google); and the presence paid through ads on website banners, blogs and social networks, sponsored links or any other type of paid content [18].

In addition, the fact that companies highlight the objectives of their digital presence to "make known the company and its products/services", by not prioritizing the communication in a more segmented way and to communicate more efficiently, seems to predict the lack of understanding of what should be the focus of digital communication and the importance that content truly acquires in the business communication strategy. In digital communication, the center ceased to be the brands, the services and the products, and became the consumer, that is, each of the Internet users and potential consumers/customers (otherwise elected figure of the year by Time magazine, in 2006) and the content itself. In 1996, Bill Gates, founder of Microsoft Corporation, stated that "Content is king," because what people look for on the web, long before they buy a service or product, they search information that solves problems and clarifies doubts. This implies that the contents created by the companies, to be effectively effective from the communication point of view, are based on three basic principles: i) Suitability to the needs and requirements of the target audience; ii) Suitability to the different digital platforms; iii) Production of appealing and creative contents that stimulate the reader's attention, involve him and identify himself with the information, brand/product or service [19]. The results obtained lead to the conclusion that the contents shared by the companies is too much focused on the sales and relativize the value that the sharing of content can confer to the brands. 
In terms of content typology, it is verified that company's value content directly related to the company's activity, which reinforces the intention that the digital presence of SMEs is almost oriented towards the dissemination of the company, its services and products. These results indicate that companies do not work, for example, strategies of Storytelling, which, although they imply the production of content indirectly related to the brand, are actually promoters of the services and products of the company, adding value, and more useful, appealing and captivating to consumers [20].

The diagnosis obtained through this study is in line with the conclusions of the study carried out by the company Produtos e Serviços de Estatística [12], which shows a very elementary stage of social and digital maturity of Portuguese SMEs. This stage can also be explained by the profile of professionals who are responsible for the management of digital content. If 11 companies outsourced this function, 76 have internal workers, but only 9 (or 11.8\%) were hired specifically for this function. In the remaining 67 (or $88.2 \%$ ) the digital content management is one of their functions (which, in 17 or $22.4 \%$ of the SME, don't have specific training for the function). This data demonstrates the lack of specific internal structures allocated to digital, which may hinder the assertive and strategic use of digital platforms and the consequent analysis of results and implementation of corrective measures, in line with an effective digital communication in the companies.

Finally, when companies are questioned about the most valued requirements when hiring a content manager/producer, the importance given to "Excellent oral and written expression in Portuguese "is verified. This appreciation reveals the understanding that the domain of digital competence is not limited to using information and communication technologies, but to use them for different purposes, such as managing information, communicating, creating and sharing content [21]. What implies mastery of another essential competence, Communication in the Mother Tongue, understood as the "ability to express and interpret concepts, thoughts, feelings, facts and opinions in both oral and written form (listening, speaking, reading and writing), and to interact linguistically in an appropriate and creative way in a full range of societal and cultural contexts; in education and training, work, home and leisure" [7].

\section{CONCLUSIONS}

The results show that SMEs are making an effort to respond to the challenges of digital communication using digital platforms. However, these companies do not seem to understand the focus of digital communication and the importance that content truly acquires in the business communication strategy. Its content is too focused on the company and its products/services and not on the needs of potential consumers.

In order for digital business communication to be effective and efficient, assertively reach the target audience, while giving value to the brand, services and products, it is essential that the digital platforms are strategically used to give visibility to the brand [14], and to the sharing content that adds value to the product/service and to the consumer himself, allowing him to solve problems and meet his needs.

However, it is important not to forget that technological evolution requires not only physical resources, but above all human resources for efficient information availability. It is imperative to have programmers, web designers to design sites that are easy and pleasant to navigate, but do not forget the presence of communication professionals who write effective content [15] (creative, appealing and adapted to the needs of potential consumers). In this perspective, it is important to emphasize the valuation by the companies surveyed of the linguistic competences in the creation of the content, which meets what is defined by the Key Competences for Lifelong Learning - A European Reference Framework, which, in addition to Digital Competence, also identifies Communication in the Mother Tongue as one of the eight core competencies needed by all individuals for personal development, active citizenship, social inclusion and employability.

This study highlights the need for ESTGA-UA, as a superior training entity, to reflect on the need to adapt the contents taught in the curricular units of these courses, in order to train professionals with knowledge and skills that will help these companies to improve their social and digital maturity. In addition, it strengthens the focus on learning oral and written language skills, as a vehicle and communication strategy in digital environments, as well as digital skills in the areas of Marketing and Communication. 


\section{REFERENCES}

[1] Portugal Digital, "Agenda Portugal Digital," 2018. Retrieved from http://www.portugaldigital.pt/index

[2] Portugal i4.0, "Indústria 4.0: Sistemas de incentivos à economia digital." Retrieved from https://www.iapmei.pt/getattachment/Paginas/Industria-4-0/Guialndustria40.pdf.aspx

[3] ACEPI and IDC, "Estudo Anual da Economia e da Sociedade Digital em Portugal: principais conclusões da Edição 2017." 2017. Retrieved from http://www.acepi.pt/downloads.php?idFicheiro=789

[4] M. P. Cunha, A. Rego, R. C. Cunha, and C. C. Cardoso, Manual de Comportamento Organizacional e Gestão. Lisboa: RH Editores, 2016.

[5] I. Amaral, "As ferramentas de comunicação 2.0 como promotoras de um consumidor ativo e participativo," in Marketing Digital \& E-commerce (J. Remondes ed.), pp. 43-58, Viseu: Psicosoma, 2016.

[6] "Portugal INCoDe.2030." Lisboa, 2017. Retrieved from http://www.incode2030.gov.pt/sites/default/files/incode2030_pt.pdf

[7] Comissão Europeia, Competências essenciais para a aprendizagem ao longo da vida: quadro de referência europeu. Luxemburgo: Serviço das Publicações Oficiais das Comunidades Europeias, 2007. Retrieved from http://ec.europa.eu/dgs/education_culture/publ/pdf/lllearning/keycomp_pt.pdf

[8] R. Vuorikari, Y. Punie, S. Carretero, and L. Van Den Brande, "DigComp 2.0: The Digital Competence Framework for Citizens," 2016. Retrieved from http://publications.jrc.ec.europa.eu/repository/bitstream/JRC101254/jrc101254_digcomp 2.0 the digital competence framework for citizens. update phase 1.pdf

[9] S. Carretero, R. Vuorikari, and Y. Punie, DigComp 2.1: The Digital Competence Framework for Citizens With eight proficiency levels and examples of use. 2017.

[10] Nações Unidas, "Building digital competencies to benefit from existing and emerging technologies, with a special focus on gender and youth dimensions: Report of the Secretary General," Geneva, 2018. Retrieved from http://unctad.org/meetings/en/SessionalDocuments/ecn162018d3_en.pdf

[11] AICEP, "As redes sociais no sucesso das empresas," Portugal global, no. 91. 2016. Retrieved from http://portugalglobal.pt/PT/RevistaPortugalglobal/2016/Documents/Portugalglobal_n91.pdf

[12] Produtos e Serviços de Estatística, "Retrato digital das PME portuguesas 2017," 2017. Retrieved from http://www.pse.pt/1o-retrato-digital-das-pme-portuguesas/

[13] Hootsuite, "Essential Insights Into Internet, Social Media, Mobile, and E-Commerce Use Around The World," 2018. Retrieved from https://digitalreport.wearesocial.com/

[14] S. Sebastião, Fundamentos da Comunicação Integrada: Organizacional e de Marketing. Lisboa: Instituto Superior de Ciências Sociais e Políticas, 2015.

[15] R. Ribeiro, A. Reis, C. Foa, P. Rodrigues, S. Alves, and S. Sebastião, Marketing para estudantes de Comunicação: Pesquisa, Estratégia e Avaliação. Lisboa: Causa das Regras, 2013.

[16] O. Blanchard, Social media ROI: Managing and measuring social media efforts in your organization. Boston: Pearson, 2011.

[17] M. V. Carrilho, "Comunicação Estratégica no ambiente comunicativo das organizações atuais," Comunicação e Sociedade, vol. 23, pp. 71-80, 2014.

[18] M. Gabriel, Marketing na era digital: conceitos, plataformas e estratégias. São Paulo: Novatec, 2010.

[19] D. M. da S. Baptista, "A importância do conteúdo na Web: para uma estratégia de comunicação eficaz," in Pelos mares da língua portuguesa III (A. M. Ferreira, C. Morais, M. F. Brasete, and R. L. Coimbra Eds.), pp. 925-944, Aveiro: UA Editora, 2017. 
[20] D. M. da S. Baptista, "Uma nova perspetiva do conto: o storytelling na estratégia da comunicação empresarial," Forma breve, no. 14, 2017.

[21] A. Ferrari, Digital competence in practice: an analysis of frameworks. Luxembourg: Publications Office of the European Union, 2012. Retrieved from http://jiscdesignstudio.pbworks.com/w/file/fetch/55823162/FinalCSReport_PDFPARAWEB.pdf

[22] J. P. Serra, "Internet e Interactividade" in Internet e Comunicação Promocional: Informação e Comunicação online (E. Camilo, Ed.), pp. 13-30, Covilhã: Universidade Beira Interior, 2003.

[23] M. Fidalgo, "Metáfora e Realidade," in Internet e Comunicação Promocional. Informação e Comunicação online (E. Camilo Ed.), pp. 63-72, Covilhã: Universidade Beira Interior, 2003. 